\title{
PANDEMIA E JUDICIALIZAÇÃO DA CRISE: A NECESSIDADE DE DIÁLOGO INSTITUCIONAL E DA OBSERVÂNCIA DA MEDICINA BASEADA EM EVIDÊNCIAS
}

\author{
Pandemic and judicialization of the crisis: the need for institutional \\ dialogue and observance of evidence-based medicine
}

\section{Arícia Fernandes Correa}

Pós-doutorado em Direito Público pela Université Paris I - Panthéon-Sorbonne. Doutora em Direito Público e Mestre em Direito da Cidade pela Universidade do Estado do Rio de Janeiro. É Professora-Adjunta de Direito e Membro Permanente do Programa de Pós-Graduação PPGDir da UERJ. Procuradora do Município do Rio de Janeiro (RJ, Brasil).

\section{Rodrigo Nóbrega Farias}

Pós-Doutorado em Direito Público pela Université Paris I - Pantheón Sorbonne. Doutor em Direito pela Universidade Estadual do Rio de Janeiro. Mestre em Direito pela Universidade Federal de Pernambuco. Professor da Universidade Estadual da Paraíba (PB, Brasil). Advogado.

\section{Resumo}

O presente artigo objetiva analisar a judicialização da saúde no Brasil e suas consequências para as políticas públicas em época de pandemia por COVID-19, enfatizando a necessidade da busca de diálogo institucional e de um debate pautado pela ciência. Com base num levantamento panorâmico das decisões do Supremo Tribunal Federal e de sua postura de selfrestraint, demonstrou-se que, de modo a preservar a harmonia entre os Poderes em tempos de combate, de todos, unidos, contra o coronavírus, promoveu-se uma deferência às escolhas dos gestores públicos, desde que lastreadas em evidencias cientificas e dados estatísticos de saúde, tendo sido criado um novo requisito de validade para o ato administrativo, em tempos pandémicos, qual seja, o de motivado na ciência, com base no principio da precaução.

Palavras-chave: Judicialização. Pandemia. Diálogo Institucional. Medicina baseada em evidências.

\begin{abstract}
This article aims to analyze the judicialization of health in Brazil and its consequences for public policies in times of pandemic by COVID-19, emphasizing the need to seek institutional dialogue and a debate guided by science. Based on a panoramic survey of the decisions of the Supreme Federal Court and its posture of selfrestraint, it was demonstrated that, in order to preserve the harmony between the Powers in times of combat, of all, united, against the coronavirus, a deference to the choices of public managers, provided that they are backed by scientific evidence and statistical health data, having created a new requirement of validity for the administrative act, in pandemic times, that is, motivated in science, based on the principle of precaution.
\end{abstract}

Keywords: Judicialization. Pandemic. Institutional Dialogue. Evidence-based medicine.

\section{Sumário}

1. O fenómeno da judicialização da saúde; 2. O Diálogo Institucional e a pandemia da Covid-19. O papel do Supremo Tribunal Federal; 3. A necessidade de observância da Medicina baseada em evidências; 4. Conclusão; 5 . Notas; Referências 


\title{
1. O FENÔMENO DA JUDICIALIZAÇÃO DA SAÚDE
}

A pandemia do coronavírus (2019-nCoV) gerou um indiscutível cenário de crise no Brasil e determinou um novo patamar no âmbito da discussão acerca do papel do Estado. Infelizmente, o direito positivo estatal é ineficaz e não atende mais ao universo complexo e dinâmico das atuais sociedades de massa, principalmente em momentos de instabilidades.

O debate sobre o crescimento do papel do Judiciário e sob algumas derivações do tema, como o controle de políticas públicas de saúde, é atual. Não há mais espaço para a tradicional abordagem do Poder Judiciário solucionando tão somente lides individuais. O juiz moderno toma decisões que atingem grande parte da comunidade e que, muitas vezes, criam normas para toda a sociedade (CAPPELLETTI, 1999, p. 57).

A presença do Poder Judiciário, em questões morais, de políticas públicas e demandas de natureza política cresce a cada dia. Debates sobre religião, direitos fundamentais, casamento entre pessoas do mesmo sexo, questões eleitorais nacionais, entre outros, estão presentes no cotidiano deste Poder.

É a denominada judicialização das relações sociais, cujos efeitos são objeto de alerta por parte Boaventura de Souza Santos:

\begin{abstract}
Tem vindo a produzir um deslocamento da legitimidade do estado: do executivo e do legislativo para o Judiciário. Esse movimento leva a que se criem expectativas elevadas as respeito do sistema judiciário, esperando-se que resolva os problemas que o sistema político não consegue resolver. Mas a criação de expectativas exageradas acerca do Judiciário é, ela própria, uma fonte de problemas (SANTOS, 2014, p. 21).
\end{abstract}

O ativismo judicial é, antes de tudo, uma atitude, uma ação do Judiciário para suprir espaços decisórios que originariamente não seriam seus, mas que não produzem os resultados esperados

Reflete, também, uma crise de confiança no atual sistema, sendo certo que o discurso de atribuição de uma atividade executiva ao Poder Judiciário pode muito bem culminar num processo de intensa erosão constitucional (STRECK, 2002, p. 161)

Na visão do Ministro Luís Roberto Barroso (2013, p. 40), a judicialização é "a deliberada expansão do papel do Judiciário, mediante o uso da interpretação constitucional para suprir lacunas, sanar omissões legislativas ou determinar políticas públicas quando ausentes ou ineficientes".

Essa postura ativa dos juízes é também ressaltada por Tate (1995, p. 33), ao afirmarem que:

condições favoráveis à judicialização só se desenvolvem porque os juízes decidem que devem (1) participar na elaboração de políticas que poderiam ser deixadas ao critério sábio ou tolo de outras instituições e, ao menos, de vez em quando, (2) substituir as soluções políticas de outras instituições por soluções políticas próprias.

O Ministro Barroso (2013, p. 242) elenca três causas principais desse fenômeno:

o reconhecimento da importância de um Judiciário forte e independente como elemento essencial para as democracias modernas... certa desilusão com a política majoritária, em razão da crise de representatividade e de funcionalidade dos parlamentos em geral.. atores políticos muitas vezes preferem que o Judi- 
ciário seja a instância decisória de certas questões polêmicas, em relação as quais exista desacordo razoável na sociedade

O fenômeno da judicialização das relações sociais reflete o crescimento do Poder Judiciário nas últimas décadas, regulando, cada vez mais, práticas e temas, antes distantes do cotidiano desse Poder.

O Judiciário passa a atuar na concretização dos direitos sociais, econômicos e culturais, nos excessos e omissões do poder público. Na saúde, o Judiciário foi ganhando espaço, paulatinamente.

A judicialização da saúde teve início na década de $90 \mathrm{com}$ as demandas judiciais propostas pelos portadores do vírus da imunodeficiência humana (HIV), em busca de fornecimento de antirretrovirais, medicamentos utilizados no tratamento da enfermidade, pelo Poder Público. O êxito na ação proposta, em 1996, pelo grupo de Apoio à Prevenção à Síndrome da Imunodeficiência adquirida contra o Estado de São Paulo, para fornecimento gratuito de medicamentos pelo poder público foi o marco inicial no tema, desencadeando a obrigação do tratamento para os portadores da doença através do Sistema Único de Saúde (SUS), bem como a inclusão da medicação nos protocolos públicos.

Não havia uma orientação padronizada dos magistrados para a matéria, nem uma discussão mais profunda sobre o tema. O resultado era uma atuação judicial individual e, quase sempre, deferindo os pleitos formulados, estimulando, por conseguinte, o uso da via judicial para a solução das demandas.

Nos últimos anos, o tema passou a fazer parte do cotidiano da sociedade brasileira, que vem transferindo ao Judiciário o papel de garantir suas expectativas sanitárias. O número de ações movidas contra o Estado pleiteando medicamentos vem crescendo significativamente.

Os professores Felipe Machado e Sulamis Dain (2012, p. 479) enumeram os quatro fatores fundamentais para a propositura das demandas judiciais em saúde:

\begin{abstract}
Insuficiência do sistema (casos em que os serviços de saúde não fornecem aqueles medicamentos que constam nas listas oficiais do SUS), 2) vazios assistenciais (casos de doenças que não têm protocolos clínicos elaborados pelo SUS, 3) confintos entre evidência científica e opinião médica (casos de prescrição de medicamentos fora da bula ou discordantes dos protocos do SUS) e 4) mercantilização da saúde.
\end{abstract}

Segundo dados do Conselho Nacional de Justiça em relatório divulgado no ano 2019 sobre a judicialização da saúde, o número de demandas judiciais relativas à saúde aumentou $130 \%$ entre 2008 e 2017 , enquanto o número total de processo judiciais cresceu $50 \%$. Segundo o Ministério da Saúde, em sete anos houve um crescimento de aproximadamente 13 vezes nos seus gastos com demandas judiciais, atingindo $\mathrm{R} \$ 1,6$ bilhão em $2016 .{ }^{1}$

Essa excessiva judicialização impede uma correta ação estatal na gestão dessas políticas públicas, no sentido de torná-las capazes de atingir seus objetivos. Nesse sentido, ressalta-se que cabe aos governos uma tarefa extremamente ampla de dirigir e de executar a Administração Pública, em atuações cada vez mais complexas e com grande nível de exigência. 
É o que leciona Maria Paula Dallari Bucci (2006, p. 39), ao estabelecer que política pública é oriunda de processos juridicamente regulados, entre eles o eleitoral e o planejamento, e deve visar à realização de objetivos relevantes e determinados, expressando a seleção de prioridades e a reserva de meios necessários; se não, vejamos:

\begin{abstract}
política pública é o programa de ação governamental que resulta de um processo ou conjunto de processos juridicamente regulados - processo eleitoral, processo de planejamento, processo de governo, processo orçamentário, processo legislativo, processo administrativo, processo judicial - visando coordenar os meios à disposição do Estado e as atividades privadas, para a realização de objetivos socialmente relevantes e politicamente determinados. Como tipo ideal, a política pública deve visar à realização de objetivos definidos, expressando a seleção de prioridades, a reserva de meios necessários à sua consecução e o intervalo de tempo em que se espera o atendimento dos resultados
\end{abstract}

Eduardo Bittar (2005, p. 388) esclarece que "pensar as políticas públicas é um desafio em tempos em que a inoperância e o descrédito tomaram conta acerca da capacidade de ação e intervenção do estado sobre a sociedade".

É imprescindível pensar em formas de alcançar a finalidade das políticas públicas, mister na área da saúde. ${ }^{2}$ É o que leciona Maria Goretti dal Bosco (2008, p. 245),

\footnotetext{
[...] compreender a política pública envolve decifrar o poder que se concentra nas mãos dos autores governamentais, verificar o desenho constitucional dos atores governamentais, verificar o desenho constitucional de cada estado no que se refere às incumbências dadas a cada qual para decidir as ações a serem praticadas e também aquelas que não serão consideradas.
}

A atuação das políticas públicas depende não só da previsão legal e vontade do Estado, mas, principalmente, do conhecimento específico, atualizado e profundo da área objeto de formulação, em um processo envolvendo poderes, agentes públicos e a sociedade.

Indubitavelmente, no âmbito do SUS, o Executivo é quem possui essa prerrogativa.

O posicionamento da jurisprudência referente à judicialização da saúde tem o Supremo Tribunal Federal como balizador do papel do Judiciário em relação ao Executivo, em dois momentos distintos, quais sejam: um antes ${ }^{3}$ e um depois das audiências públicas para tratar do tema ocorrido nos meses de abril e maio de 2009.

Com o debate, pretendia-se obter esclarecimentos de diversos setores da sociedade sobre as questões técnicas, científicas, administrativas, políticas, econômicas e jurídicas, envolvendo o direito à saúde. Após a realização das audiências públicas, o Supremo Tribunal Federal, sob a relatoria do Ministro Gilmar Mendes, criou parâmetros para o tema, ao julgar o leading case nos autos do AgRg na STA 175-CE. ${ }^{4}$

Nesse julgamento, fruto dos debates ocorridos nas audiências públicas, a Corte concluiu que, apesar de ser atribuído ao Judiciário a responsabilização pela judicialização da saúde, essa refleteria, na verdade, a crise do Sistema Único de Saúde. As decisões judiciais seriam, em vários casos, a única garantia de prestação de direitos sociais, especialmente do direito à saúde. O principal problema seria, tão somente, a efetivação de políticas já asseguradas pelo Sistema Único de Saúde, portanto, passíveis de judicialização. ${ }^{5}$

Mais recentemente, dois novos posicionamentos do STF influenciaram diretamente a decisão acerca da judicialização: a decisão proferida no RE 657.718 (Repercussão - Tema 
500), em 22/05/2019, acerca do fornecimento de medicamentos experimentais, e a decisão de 11 de março de 2020, (Repercussão - Tema 06) sobre medicamentos de alto custo.

Em maio de 2019, apreciando o RE $657.718,{ }^{6}$ o Supremo uniformizou o entendimento acerca da concessão de medicamentos experimentais, que ficou assim consignada no Tema 500:

\begin{abstract}
1. O Estado não pode ser obrigado a fornecer medicamentos experimentais. 2. A ausência de registro na ANVISA impede, como regra geral, o fornecimento de medicamento por decisão judicial. 3. É possível, excepcionalmente, a concessão judicial de medicamento sem registro sanitário, em caso de mora irrazoável da ANVISA em apreciar o pedido (prazo superior ao previsto na Lei $n^{\circ}$ 13.411/2016), quando preenchidos três requisitos: (i) a existência de pedido de registro do medicamento no Brasil (salvo no caso de medicamentos órfãos para doenças raras e ultrarraras);(ii) a existência de registro do medicamento em renomadas agências de regulação no exterior; e (iii) a inexistência de substituto terapêutico com registro no Brasil. 4. As ações que demandem fornecimento de medicamentos sem registro na ANVISA deverão necessariamente ser propostas em face da União.
\end{abstract}

No que se refere aos medicamentos de alto custo, o plenário do STF (Supremo Tribunal Federal) decidiu, em março deste ano, que o poder público não tem a obrigação de fornecer medicamentos de alto custo com registro na Anvisa (Agência Nacional de Vigilância Sanitária) que não integram a lista do SUS (Sistema Único de Saúde). ${ }^{7}$

Diante de todo esse cenário, o CNJ vem estimulando uma atuação mais criteriosa e responsável do Judiciário, através de uma verdadeira política de saúde. O inchaço do Poder Judiciário $^{8}$ alerta para o despreparo técnico dos juízes, ao lidar com pedidos referentes à saúde, principalmente medicamentos, cujas propriedades terapêuticas desconhecem. Nessa conjuntura, o Conselho Nacional de Justiça (CNJ) estimulou medidas para constituição de núcleos de apoio técnico ao Judiciário, composto por médicos e farmacêuticos para ajudar nas questões clínicas apresentadas.

\title{
2. O DIÁLOGO INSTITUTICIONAL E A PANDEMIA DA COVID-19. O PAPEL DO SUPREMO TRIBUNAL FEDERAL
}

A judicialização da saúde criou um paradoxo: a busca de um sistema pleno, eficaz, moderno e ilimitado para aqueles que teriam acesso à Justiça, enquanto os demais usuários do sistema convivem com o cenário de escassez.

A competência conferida ao Judiciário, para a solução de conflitos em última instância, proferindo decisões de caráter definitivo sobre aplicações e interpretações de normas constitucionais, garante-lhe um papel importante nas democracias modernas. O debate sobre a ideia da supremacia judicial não é recente, originando-se com a posição do "Justice" John Marshall, na decisão do caso "Marbury v. Madison", que reconheceu a Constituição como a norma superior do ordenamento jurídico, tendo, como guardião, o Poder Judiciário, especificamente, a Suprema Corte.

Cass Sunstein - já conhecido por sua inovadora revisão sobre os custos do direito - e Adrian Vermeule, professores da Faculdade de Direito da Universidade de Harvard, buscaram, em estudo sistemático, apresentar críticas concretas à ideia de supremacia judicial. Em primeiro lugar, formularam objeções, aos teóricos, sobre o papel que exigem dos juízes, 
reconhecendo que, embora certos comportamentos hermenêuticos desses, baseados em princípios amplos e vagos, sejam buscados por aqueles, o magistrado é um ser humano normal, com restrições intelectuais e, principalmente, de tempo, para se dedicar à tarefa de julgar na forma propugnada pelos acadêmicos (SUNSTEIN; VERMEULE, 2003, p. 885). Até mesmo a organização judiciária e a existência de processos repetitivos pode dificultar a dedicação a casos importantes ou paradigmáticos.

No artigo "Interpretation and institutions", os professores Sunstein e Vermeule alertaram, ainda, sobre o problema da amplitude e do excesso de teorização das decisões judiciais e as consequências decorrentes dela, concluindo que os magistrados deveriam buscar soluções práticas e específicas para o caso. A postura maximalista, mesmo bem fundamentada, segundo os pesquisadores americanos, pode ser inadequada para determinado momento da sociedade ou mesmo antidemocrática (SUNSTEIN; VERMEULE, 2003, p. 886). Os autores defendem uma postura modesta e humilde do Judiciário, de modo que os juízes reconheçam as limitações à sua capacidade interpretativa, impedindo posições antagônicas radicais e estimulando uma postura lenta e mais conservadora desse Poder.

Nesse contexto, o modelo americano de Suprema Corte, o qual inspirava os debates sobre a supremacia judicial, recebeu, nos últimos anos, o contraponto do modelo canadense, que passou a ser aplicado em países como a África do Sul, a Nova Zelândia e Israel (DODEK, 2007, p. 317).

No Canadá, a institucionalização do diálogo entre poderes, como forma de superar a crítica ao caráter contramajoritário do Judiciário, foi impulsionada com a adoção, na Constituição de 1982, da cláusula do "notwithstanding", mecanismo que admite uma resposta do Legislativo a uma decisão da Corte Suprema do país, com a consequente superação da decisão judicial pela deliberação legislativa. ${ }^{9}$

Mais de quinze anos após a inovação canadense, Peter Hogg e Allison Bushell (1997, p. 96 e ss.), em artigo sobre o uso desse novo modelo de controle de constitucionalidade como forma de estabelecer uma forma de diálogo entre poderes, chamou a atenção para o fato de que este foi capaz de estimular a reflexão do Legislativo sobre a constitucionalidade de uma lei e, em muitas vezes, superá-la, por meio de um debate público e qualificado. Estabeleceu-se, então, uma nova forma de decisão, pois não há uma instância final, cabendo sempre uma nova intervenção, em um diálogo público sobre os valores efetivamente protegidos pela Constituição.

O debate público e transparente estimula o caráter democrático do sistema, sendo certo que numa conjuntura como estamos vivendo, a judicialização pode gerar consequências muito sérias em todo o sistema de saúde. Pode significar a vida para alguns, em detrimento da morte para outros.

Na realização de políticas públicas ou na concretização de direitos fundamentais pelo Executivo, semelhante conversação permite chegar a consensos, mesmo em questões controversas. Apesar disso, sempre que a comunhão de ideias não for possível, é importante lembrar que a atuação desses Poderes deve zelar pela não-interferência na incumbência originalmente atribuída aos outros dois. Eis a necessidade de um "intervencionismo judicial 
mais responsável" (HABER NETO, 2013, p. 188), o qual possa garantir um "contraditório comparticipativo" (THEODORO JÚNIOR et al., 2013, p. 131) e dialógico.

Enfocando a judicialização da saúde, tem-se que o Poder Judiciário, em sua atuação, influencia, de modo relevante, a implementação das políticas públicas do setor, pois, ao decidir sobre a efetivação de determinada medida pública, a Justiça age em meio à omissão dos administradores públicos, ou mesmo os substitui, antecipando-se às decisões executivas. ${ }^{10}$

No que se refere à crise da COVID-19, é importante destacar, até agora, de forma majoritária, ${ }^{11}$ a presença de um Poder Judiciário ativo, ágil, mas com espírito cooperativo, não buscando o protagonismo,; se não, vejamos:

Em 17 de março, o Presidente do Supremo Tribunal Federal, Ministro Dias Toffoli, junto com outros Ministros da Suprema Corte, o Presidente do Senado, Davi Alcolumbre, e o Presidente da Câmara dos Deputados, Rodrigo Maia, discutiram, com objetivo de conferir segurança jurídica, medidas emergenciais a serem aprovadas pelo Legislativo. ${ }^{12}$

Em vários estados, comitês institucionais de combate ao coronavírus foram criados, envolvendo Executivo, Legislativo, Judiciário, $\mathrm{OAB}$, associações médicas, entre outras, para juntos, apresentarem soluções coletivas na solução dos graves problemas.

É importante destacar, principalmente, a atuação do STF nesta crise sanitária que estamos vivendo.

Com efeito, somente até 02 de abril neste ano, tramitavam na Corte mais de 400 ações, entre ADI's, mandados de seguranças, ACO's, ADPF's, entre outros instrumentos aptos a abordar a crise pandêmica que estamos vivendo, questionando ou pleiteando em resumo: a) suspensão por 180 dias das dívidas dos Estados com a União; b) inconstitucionalidade do calendário eleitoral e a necessidade de suspensão do processo eleitoral de 2020 , ante os impactos decorrentes da crise sanitária; c) suspensão da MP 927/20, que autoriza empregadores a adotar medidas excepcionais em razão da calamidade pública; d) afastamento da exigência e adequação orçamentária (Lei de Responsabilidade Fiscal), em relação à criação e expansão de programas destinados ao enfrentamento do coronavírus; e) suspensão dos efeitos da EC 95/2016, afastando o teto de gastos do campo da saúde; f) suspensão de pontos de medidas provisórias que legislam sobre transporte público municipal; g) a Lei Federal n. 13.979/2020, que outorga competência à União Federal para fazer requisições administrativas para utilização de leitos de UTI's na rede privada; h) a instituição, por decisão judicial, da renda básica mínima; i) ações e omissões do poder público federal na condução de políticas públicas de pandemia; j) a legalidade de publicidade nas redes sociais do Presidente da República denominada "O Brasil não pode parar"; k) a eficácia do artigo da MP 928/20, que limitou o acesso à informações de órgãos públicos, durante a emergência em saúde pública; I) destinação de $\mathrm{R} \$ 1.6$ bilhão de reais ao Ministério da Saúde, para combate à pandemia, decorrente de valores da operação Lava Jato; $\mathrm{m}$ ) a dissimenação do coronavierus nas prisões; $n$ ) a competência dos Estados e Municípios para estabelecer medidas de enfrentamento à crise; o) a possibilidade de determinação de proibição de entrada de voos no Brasil provenientes de países afetados pela pandemia e controle de fluxo de 
pessoas nas fronteiras brasileiras; p) pedidos para que os recursos dos Fundos Especiais de Financiamento de Campanha e de Assistência Financeira aos Partidos Políticos sejam destinados ao combate à pandemia; q) pedidos de suspensão das cobranças de pedágio nas rodovias federais do Brasil, enquanto perdurar a pandemia; r) pedidos de prorrogação e alteração dos prazos de inscrição e normas aplicáveis para o exame do ENEM de 2020.

As decisões até aqui tomadas não foram de confronto com o Poder Executivo ou mesmo com o Poder Legislativo, muito pelo contrário; o que vem imperando nestas decisões é a ideia de que o Poder Executivo deve buscar implementar as orientações emanadas dos órgãos técnicos de saúde, da Organização Mundial de Saúde e do próprio Ministério da Saúde, ou seja, deve prevalecer o juízo técnico das autoridades administrativas competentes, deve haver respeito às diretrizes técnicas, aos dados e estudos técnicos e às diretrizes que a ciência e a comunidade científica têm produzido diariamente, sendo que o ônus da política de combate a COVID-19 é do Poder Executivo, que é composto por membros democraticamente eleitos e que foram, pela vontade do povo, investidos em mandato eletivo.

Prevaleceu, assim, a própria exigência legal contida na Lei Federal n. 13.979/2010, segundo a qual:

\begin{abstract}
Art. $3^{\circ}$ Para enfrentamento da emergência de saúde pública de importância internacional decorrente do coronavírus, poderão ser adotadas, entre outras, as seguintes medidas:

[...]

$\S 1^{\circ}$ As medidas previstas neste artigo somente poderão ser determinadas com base em evidências científicas e em análises sobre as informações estratégicas em saúde e deverão ser limitadas no tempo e no espaço ao mínimo indispensável à promoção e à preservação da saúde pública.
\end{abstract}

No julgamento da Arguição de Descumprimento de Preceito Fundamental n. 672/DF, a Corte Suprema, entendendo que a política pública de saúde consistiria de preceitos fundamentais que poderiam estar sendo violados, assim como o princípio federativo e a separação dos poderes, reconheceu a competência concorrente de Estados e Distrito Federal e, suplementar, dos Municípios, para tratar de saúde (art. 23, inc. II e IX) e, portanto, do combate ao coronavírus, com fundamento nos artigos 24 , inc. XII c/c $25, \S 1^{\circ} \mathrm{c} / \mathrm{c} 30$, inc. II, da Constituição, de modo que assegurou aos governos estaduais, distrital e municipais, no exercício de suas atribuições e no âmbito de seus territórios, competência para a adoção ou manutenção de medidas restritivas durante a pandemia da Covid-19, tais como a imposição de distanciamento social, suspensão de atividades de ensino, restrições de comércio, atividades culturais, circulação de pessoas, entre outras.

$\mathrm{Na}$ linha da proteção e prevenção aos riscos à saúde provocados pelo perigo de contágio pelo vírus SARS-CoV-2, o que o Judiciário exigiu foi que as medidas fossem lastreadas em dados científicos ou estatísticos que os justificassem.

Com efeito, se o ato normativo se legitimou pela decisão da Corte Suprema de Justiça, o ato administrativo passou a contar com um novo requisito de validade: o de estar lastreado em evidências científicas ou dados estatísticos de saúde aptos a justificar e legitimar perante a sociedade, o que mais tarde veio a ser enfaticamente reconhecido pelo Supremo Tribunal Federal, sob pena de responsabilidade do agente público. 
Com efeito, nos julgamentos das ações diretas de inconstitucionalidade ${ }^{13}$ acerca da Medida Provisória n. 966/2020, a Corte Suprema entendeu que os atos de agentes públicos, em relação à pandemia da Covid-19, devem observar critérios técnicos e científicos de entidades médicas e sanitárias, observando-se, assim, o princípio da precaução. A Corte julgou que o artigo $2^{\circ}$ da referida Medida Provisória deveria ser interpretado conforme a Constituição, para que se configure como erro grosseiro o ato administrativo que ensejar violação do direito à vida, à saúde ou ao meio ambiente equilibrado em razão da inobservância de normas e critérios científicos e técnicos.

Coube, assim, aos Entes Públicos, a partir de evidências científicas e de dados estratégicos de saúde relativos a indicadores como índice de letalidade do vírus, posicionamento da curva de crescimento dos contagiados e nível de ocupação de leitos pelos atingidos pelo coronavírus, definir as raras atividades que poderiam ser total ou parcialmente exercidas, ficando todas as demais qualificadas como não essenciais e, quem as exercia, sujeitas à quarentena ou isolamento.

O que restou claro foi que o STF evitou, neste momento, atos interventivos da competência dos demais poderes, ao decidir não suspender as eleições de $2020,{ }^{14}$ o que terminou pela aprovação, pelo Poder Legislativo, da Emenda Constitucional n 107/2020; ao não deferir a instituição de uma renda básica emergencial, ${ }^{15}$ por entender que não cabe ao Poder Judiciário a fixação de auxílio temporário e que a matéria está sendo tratada pelos poderes Executivo e Legislativo ou mesmo não interferir na condução das políticas de prevenção nos presídios. $^{16}$

Ao que parece, o Poder Judiciário adotou um papel de selfrestraint, julgando sempre com cautela, serenidade e responsabilidade, sem desrespeitar ou ferir a necessária independência dos demais poderes da República ou mesmo sem querer invadir o poder discricionário da Administração Pública - agora em parte vinculado, uma vez que qualificado pela necessidade de estar lastreado em evidencias científicas ou dados estatísticos de saúde para desfrutar de validade -, mas procurando prestigiar as escolhas administrativas tomadas pelos órgãos técnicos do Estado e pugnando para que o próprio Estado decidisse em consonância com as normas e critérios científicos e técnicos aplicáveis à matéria, tais como estabelecidos por organizações e entidades médicas e sanitárias, reconhecidas nacional e internacionalmente, não querendo substituir o gestor público nas decisões tomadas, notadamente naquelas questões técnicas ou científicas, que devem estar fora do âmbito de avaliação do Judiciário, como constatado pela doutrina Chevron. ${ }^{17} 18$

Há necessidade de um Judiciário remodelado, apto a ouvir e a compreender divergências e dificuldades, reconhecendo que a aplicação é apenas uma das etapas para a efetivação do direito. Conforme lembram Theodoro Júnior et al. (2013, p. 131), a o diálogo deve ser estendido também à fase de conhecimento das lides envolvendo direitos prestacionais: "Se tratamos da implantação de políticas públicas, então o 'público' que será atingido pela mesma [decisão judicial] deve ter tido oportunidade de participar não apenas na fase executiva, mas também na cognição".

É importante que, durante a pandemia da COVID-19, tenha-se um franco e honesto 
diálogo entre os poderes, privilegiando os experts e seus estudos técnicos e científicos, expondo-se as particularidades do contexto em que se encontra inserta a situação da saúde em âmbito local, na crise que estamos vivendo.

\title{
3. A NECESSIDADE DA OBSERVÂNCIA DA MEDICINA BASEADA EM EVIDÊNCIAS
}

Além do diálogo institucional, a atuação do Judiciário nesta pandemia passa também pela observância da Ciência. A judicialização de um medicamento impõe a comprovação da eficácia do mesmo à luz da medicina baseada em evidências, que poderia ser definida como "o elo entre a boa pesquisa científica e a prática clínica. Em outras palavras, a MBE utiliza provas científicas existentes e disponíveis no momento, com boa validade interna e externa, para a aplicação de seus resultados na prática clínica." (EL DIB, 2007).

A saúde baseada em evidências busca a melhor qualidade de informação para auxiliar no processo de decisões médicas. Ora, na hipótese do novo vírus, não há indicação técnica para o uso da cloroquina, de acordo com a medicina baseada em evidências. Esse é o posicionamento majoritário dos órgãos técnicos nesse momento, em todo o mundo, incluindo a ANVISA e a Organização Mundial de Saúde.

Vejamos a transcrição do voto do Ministro Barroso, ${ }^{19}$ ao mencionar o quarto requisito para a judicialização de medicamentos, in verbis:

\begin{abstract}
Em quarto lugar, deve-se exigir a comprovação de eficácia do medicamento pleiteado à luz da medicina baseada em evidências. O deferimento de pleitos judiciais por fármacos não incluídos na política pública existente, nem nos protocolos clínicos deve se dar apenas quando houver segurança científica em relação à sua eficácia e adequação.

A decisão judicial que defere o pedido de dispensação de medicamentos não incorporado pelo Sistema Único de Saúde jamais pode se basear em um único laudo ou prescrição médica, sem que se apontem evidências científicas confiáveis de que o fármaco pleiteado é realmente eficaz para o tratamento da doença do paciente em questão. Se a lei exige que a decisão de incorporação (ou a negativa de incorporação) de fármaco ao SUS tenha como fundamentos critérios técnicos-científicos, não se deve permitir que esses requisitos sejam simplesmente ignorados pelo Poder Judiciário no âmbito de demandas individuais.

Portanto, quando não houver prova de que o medicamento pleiteado não incorporado pelo SUS não for eficaz à luz da medicina baseada em evidências, não é possível deferir o fármaco inicialmente pleiteado
\end{abstract}

Nesse particular, é importante ressaltar o papel da assistência farmacêutica no âmbito do SUS como um processo que inclui as etapas de seleção, programação, aquisição, armazenamento, distribuição e utilização e, ainda, atividades como a pesquisa e o desenvolvimento, a produção e o registro sanitário. O cumprimento da etapa da avaliação de sua utilização é indispensável para a própria segurança do paciente e não uma mera fase burocrática. $^{20}$

A inserção de novos medicamentos, ou sua utilização para fins diversos do previsto, no protocolo do SUS, sem utilizar-se da medicina baseada em evidências, além de incorreta do ponto de vista técnico-farmacêutico, desconsidera a necessidade de compreensão sistêmica e coletiva da saúde pública. Esse é o alerta do professor Ricardo Augusto Dias da Silva (2013, p. 436): 
com efeito, nas hipóteses de dispensação medicamentosa que esteja fora da padronização estabelecida pelo SUS, corre-se o risco de alterar uma alocação de recursos financeiros para poucos em detrimento de benefícios que poderiam destinar-se a muitos cidadãos, destacando-se que as padronizações e os protocolos estabelecidos pelo SUS estão baseados em evidências científicas comprovadas por análises estatísticas disponíveis na literatura científica.

Essa também é a opinião de Sarlet e Figueiredo (2013, p. 44), ressaltando a importância de defesa da legitimidade do procedimento de inserção dos medicamentos no âmbito do SUS:

\begin{abstract}
isso porque os protocolos clínicos e as diretrizes terapêuticas do SUS, que uniformizam as condutas de tratamento no âmbito do sistema de saúde brasileiro tem por base o trabalho de profissionais especializados, buscando (pelo menos vale, em princípio, a presunção) acima de tudo, a garantia de eficiência e segurança dos tratamentos e medicamentos indicados, encontrando-se abertos a participação da comunidade científica, a quem é viabilizada a possibilidade de opinar sobre o protocolo em estudo, antes que seja definitivamente aprovado e estabelecido.
\end{abstract}

A assistência farmacêutica no SUS tem, como diretriz, o fornecimento universal de medicamento, mas, para alcançar essa universalidade, adota critérios de programação ${ }^{21}$ rigorosa envolvendo todas as necessidades coletivas e a definição de adequação, de custo e de efetividade do medicamento.

Repita-se, em período de crise como estamos, a exigência de embasamento técnico por parte dos magistrados, ao decidir sobre a materia de saúde, que acarretará, direta ou indiretamente, alterações nas políticas públicas de combate à COVID-19, é indispensável.

O professor Georges Abboud 22 assim preconiza:

\begin{abstract}
Muito se fala, no Brasil de 2020, em "conversas institucionais" e "diálogo entre poderes". Justiça seja feita: é a postura mais importante que qualquer Estado pode adotar para impedir a criação de planos incompatíveis e mal pensados, que se excluem uns aos outros. O entusiasmo por essas noções às vezes se esquece de uma verdade acaciana: dialogar é também escutar. Aqui, "escutar" significa humildade e consciência das próprias limitações constitucionais. Assim, cabe ao Executivo definir as medidas de controle da pandemia, que deve encontrar uma resposta rápida do Legislativo, em matérias que fujam da sua alçada natural.
\end{abstract}

Indubitavelmente, o Judiciário, ao lidar com esta crise, tem de aprimorar sua atuação técnica na área da saúde pública, compreendendo-a em sua visão coletiva, sistêmica e integral e, também, incorporando o direito à saúde como parte de uma política pública de responsabilidade não só do Executivo, mas do Judiciário e da sociedade.

\title{
4. CONCLUSÃO
}

A judicialização não confere solução plena no âmbito dos conflitos da saúde. Devem-se buscar alternativas institucionais, através do envolvimento de todos os atores relacionados, direta ou indiretamente, ao tema, na busca de consensos para a efetivação do direito fundamental à saúde. (FARAIS, 2018, p. 119).

A inserção de novos atores, retirando o caráter unilateral da condução da administração, é inerente à gestão da saúde. Pluralismo e participação nas decisões são marcas do modelo de saúde concebido pela Constituição. A participação, dentro do sistema normativo concebido para a saúde pública, assume um caráter de dever, de responsabilização na for- 
mulação e fiscalização das políticas de saúde.

A luta pela saúde pública nesta crise da COVID-19 passa pela observância da Ciência e pelo estímulo a novas formas de diálogo, a fim de que a sociedade seja a protagonista e, não, o Poder Judiciário, objetivando a efetivação de políticas públicas de saúde emergenciais. O principal recurso para esta finalidade está na busca de harmonia, por meio de práticas consensuais, entre os diversos atores de sua judicialização.

\section{NOTAS}

1. INSTITUTO DE ENSINO E PESQUISA (INSPER). Judicialização da Saúde no Brasil: Perfil das Demandas, Causas e Propostas de Solução. Brasília, DF: Conselho Nacional de Justiça, 2019. Disponível em: https://www.cnj.jus.br/wp-content/uploads/2019/03/66361404dd5ceaf8c5f7049223bdc709.pdf. Acesso em: 3 abr. 2020.

2. Especificamente no tocante às políticas públicas de saúde, Lucília Alcione Prata (2013, p. 258) ressalta que essas possuem características distintas das demais políticas públicas "são políticas de Estado, cujas garantias, cujos princípios e metas são previamente estabelecidos na Constituição, e quaisquer políticas que venham a ser implementadas encontram-se constitucionalmente vinculadas aos princípios constitucionais da proteção universal e integral a saúde e demais princípios, garantias e objetivos traçados na Constituição".

3. Antes das audiências públicas, o STF resguardava várias decisões reconhecendo a garantida do direito à saúde, sendo as mais citadas as proferidas na petição n. 1.246-1, e no Agravo Regimental em Recurso Extraordinário (AgRgRE) n. 271.286-8-RS, relatado pelo Ministro Celso de Mello, e a AgRgRE n. 255.627$1-R S$, relatada pelo Ministro Nelson Jobim.

4. A decisão foi assim ementada: "Suspensão de Segurança. Agravo Regimental. Saúde pública. Direitos fundamentais sociais. Art. 196 da Constituição. Audiência Pública. Sistema Único de Saúde - SUS. Políticas públicas. Judicialização do direito à saúde. Separação de poderes. Parâmetros para solução judicial dos casos concretos que envolvem direito à saúde. Responsabilidade solidária dos entes da Federação em matéria de saúde. Fornecimento de medicamento: Zavesca (miglustat). Fármaco registrado na Agência Nacional de Vigilância Sanitária (ANVISA). Não comprovação de grave lesão à ordem, à economia, à saúde e à segurança públicas. Possibilidade de ocorrência de dano inverso. Agravo regimental a que se nega provimento" (STF - STA: 175 CE, Relator: Min. Gilmar Mendes (Presidente), Data de Julgamento: 17/03/2010, Tribunal Pleno, Data de Publicação: DJe-076 DIVULG 29-04-2010 PUBLIC 30-04-2010 EMENT VOL-02399-01 pp-00070. Disponível em: http://stf.jusbrasil.com.br/jurisprudencia/9087079/agreg-na-suspensao-de-tutela-antecipada-sta-175-ce. Acesso em: 10 abr. 2015.

5. Esse foi o entendimento destacado no voto do relator "Após ouvir os depoimentos prestados pelos representantes dos diversos setores envolvidos, ficou constatada a necessidade de se redimensionar a questão da judicialização do direito à saúde no Brasil. Isso porque, na maioria dos casos, a intervenção judicial não ocorre em razão de uma omissão absoluta em matéria de políticas públicas voltadas à proteção do direito à saúde, mas tendo em vista uma necessária determinação judicial para o cumprimento de políticas já estabelecidas. Portanto, não se cogita do problema da interferência judicial em âmbitos de livre apreciação ou de ampla discricionariedade de outros Poderes quanto à formulação de políticas públicas. Esse foi um dos primeiros entendimentos que sobressaiu nos debates ocorridos na Audiência Pública - Saúde: no Brasil, o problema talvez não seja de judicialização ou, em termos mais simples, de interferência do Poder Judiciário na criação e implementação de políticas públicas em matéria de saúde, pois o que ocorre, na quase totalidade dos casos, é apenas a determinação judicial do efetivo cumprimento de políticas públicas já existentes".

6. BRASIL. Supremo Tribunal Federal. RE 657.718/MG. Relator: Min. Marco Aurélio, 25 de outubro 
de 2019. Diário de Justiça Eletrônico, Brasília, DF, n. 232, ata n. 162/2019, 25 out. 2019. Disponível em: http://www.stf.jus.br/portal/jurisprudenciaRepercussao/verAndamentoProcesso.asp?incidente $=4143144$ \&numeroProcesso $=657718$ \&classeProcesso=RE\&numeroTema $=500$. Acesso em: $17 \mathrm{abr}$. 2020. (STF - RE 657.718, Relator: Min. Marco Aurélio. Publicação DJE 25/10/2019- ata n. 162/2019, DJE n. 232, divulgado em 24/10/2019).

7. BRASIL. Supremo Tribunal Federal. Recurso Extraordinário 566.471/RN. Relator: Min. Marco Aurélio, 11 de março de 2012. Brasília: STF, 2012. Disponível em: http://www.stf.jus.br/arquivo/cms/noticiaNoticiaStf/anexo/RE566471.pdf. Acesso em: 17 abr. 2020.

8. Essa expressão foi utilizada pelo Conselheiro do Conselho Nacional de Justiça, Joaquim Falcão, 2007. Disponível em: http://www.ibrajus.org.br/revista/artigo.asp?idArtigo=95. Acesso em: 14 abr. 2020.

9. "Juntas, as limitações da Carta e as cláusulas 'notwithstanding' criam um modelo unicamente canadense de proteção de direitos constitucionais. A Carta acrescentou uma nova alternativa ao tradicional debate entre a supremacia judicial, tal como idealizada nos Estados Unidos, e a supremacia legislativa, representada pelo clássico Parlamento inglês. A Carta demonstra a existência de um espectro entre esses dois polos e insere o modelo canadense em algum lugar entre eles. $O$ modelo canadense abriu as possibilidades constitucionais de proteção aos direitos, em vez de prover um protótipo definitivo a ser imposto ou adotado como uma estrutura pré-fabricada. Particularmente, o mecanismo 'notwithstanding' permitiu a possibilidade de contribuição legislativa à interpretação de direitos e vários mecanismos foram desenvolvidos sobre tais bases". Tradução nossa do original em ingles: "Together, the Charter's limitations and the notwithstanding clauses create a uniquely Canadian model of constitutional rights protection. The Charter added a new alternative into the traditional debate between judicial supremacy as idealized by the United States and legislative supremacy epitomized by the classic Westminster Parliament. The Charter demonstrated the existence of a spectrum between these two poles and planted the Canadian model somewhere between them. The Canadian model opened up the constitutional possibilities for rights protection rather than providing a definitive prototype to be imposed or adopted like a prefabricated structure. In particular, the notwithstanding mechanism invited the possibility of legislative contribution to rights interpretation and various mechanisms have been developed along such lines" (DODEK, 2007, p. 319).

10. A interferência excessiva e desorganizada pode viciar, ou prejudicar a atividade executiva. "Diante do aumento exponencial da judicialização de políticas públicas, o Estado tende a permanecer numa 'inércia funcional', isto é, 'só atua se for pressionado pelo Judiciário'" (THEODORO JÚNIOR et al, 2013, p. 123).

11. O argumento refere-se, tão somente, à atuação do Supremo Tribunal Federal. Há, por outro lado, inúmeras decisões judiciais intervencionistas e desproporcionais emanadas, dentro da crise do COVID-19, da Justiça Estadual, Federal e do Trabalho.

12. O Congresso Nacional, através da Câmara e Senado, aprovaram por unanimidade e em tempo recorde, medidas provisórias sobre a matéria, decreto de calamidade púbica, créditos extraordinários, liberação de recursos para o Fundo Nacional de Saúde. (CORONAVÍRUS: Ministro da Saúde reúne-se com presidentes do Congresso e do Supremo Tribunal Federal. Brasília: Senado Notícias, 17 mar. 2020. 1 vídeo (2 min). Publicado por Senado Federal. Disponível em: https://www12.senado.leg.br/noticias/videos/2020/03/legislativo-judiciario-e-executivo-discutem-medidas-diante-da-emergencia-do-coronavirus. Acesso em: 30 mar. 2020).

13. As ações foram ajuizadas pela Rede Sustentabilidade (ADI 6421), pelo Cidadania (ADI 6422), pelo Partido Socialismo e Liberdade (ADI 6424), pelo Partido Comunista do Brasil (ADI 6425), pela Associação Brasileira de Imprensa (ADI 6427), pelo Partido Democrático Trabalhista (ADI 6428) e pelo Partido Verde (6431).

14. STF - ADI 6359 Relator: Min. Rosa Weber. Decisão publicada no DJE em 02/04/2020. Disponível em: http://www.stf.jus.br/arquivo/cms/noticiaNoticiaStf/anexo/ADI6359.pdf. Acesso em: 2 abr. 2020.

15. STF - ADO 56 Relator: Min. Marco Aurélio. Decisão proferida em 31/03/2020. Disponível em: http:// 
portal.stf.jus. br/processos/detalhe.asp?incidente=5883259. Acesso em: 2 abr. 2020 .

16. STF - ADPF 347 Relator: Min. Marco Aurélio. Decisão publicada no DJE em 02/04/2020. Disponível em: http://portal.stf.jus.br/processos/detalhe.asp?incidente=4783560. Acesso em: 2 abr. 2020

17. Na apreciação judicial de atos das agencias reguladoras, no âmbito do direito norte-americano, deveriam ser respeitados dois standards principais, firmados a partir do caso Chevron, Inc v. Natural Resources Defense Concil: i) a preferência à intenção legislativa quando claro o texto normativo, à qual deveriam se curvar o Judiciário e as Agências e ii) a verificação da razoabilidade da interpretação conferida pela agência reguladora quando silencioso, ambíguo ou obscuro o texto legal, o que aqui aplicar-se-ia, mutatis mutantis, na relação entre Judiciario e Executivo em relação àa decisões normativas e adminkistrativas relacionadas ao combate ao contagio da população por Covid-19.

18. 467 U.S. 837 (1984) Chevron se tornou um dos casos mais citados do direito norte-americano de todos os tempos. Até Dezembro de 2001, teria sido citado nas cortes federais mais de 7000 vezes, muito mais do que três casos mais antigos e mais conhecidos, Brown v. Board of Education, Roe v. Wade e Marbury v. Madison. (BREYER, Stephen et al. Administrative Law and Regulatory Police. New York: Aspen Publishers, 2002, p. 289 - tradução livre).

19. BRASIL. Supremo Tribunal Federal. Recurso Extraordinário 566.471/RN. Relator: Min. Marco Aurélio, 11 de março de 2012. Brasília: STF, 2012. Disponível em: http://www.luisrobertobarroso.com.br/ wp-content/uploads/2016/10/RE-566471-Medicamentos-de-alto-custo-versão-final.pdf. Acesso em: 7 abr. 2020.

20. O artigo 1, III, da Resolução Normativa n. 338 de 2004, do Conselho Nacional de Saúde, define a Assistência Farmacêutica como sendo "um conjunto de ações voltadas à promoção, proteção e recuperação da saúde, tanto individual como coletivo, tendo o medicamento como insumo essencial e visando o acesso e ao seu uso racional. Este conjunto envolve a pesquisa, o desenvolvimento e a produção de medicamentos e insumos, bem como a sua seleção, programação, aquisição, distribuição, dispensação, garantia da qualidade dos produtos e serviços, acompanhamento e avaliação de sua utilização, na perspectiva da obtenção de resultados concretos e da melhoria da qualidade de vida da população".

21. Vera Lúcia Pepe ressalta que a etapa de programação "objetiva a garantia da disponibilidade dos medicamentos selecionados, nas quantidades adequadas e no tempo oportuno, para atender as necessidades da população, num determinado período de tempo. Ela é importante para a correta alocação dos recursos disponíveis e para evitar a descontinuidade no abastecimento." (PEPE, 2010). Disponível em: http://www.scielo.br/scielo.php?script=sci_arttext\&pid=S1413-81232010000500015\&lng=en\&nrm=iso. Acesso em: 8 abr. 2015.

22. ABBOUD, Georges. Como decidir em tempos de crise? O Estado de S. Paulo, São Paulo, 30 abr. 2020. Estado da Arte. Disponível em: https://estadodaarte.estadao.com.br/como-decidir-tempos-crise/. Acesso em: 5 jul. 2020.

\section{REFERÊNCIAS}

ABBOUD, Georges. Como decidir em tempos de crise? O Estado de S. Paulo, São Paulo, 30 abr. 2020. Estado da Arte. Disponível em: https://estadodaarte.estadao.com.br/como-decidir-tempos-crise/. Acesso em: 5 jul. 2020.

ASENSI, Felipe Dutra. Judicialização da saúde e conselho nacional de justiça - perspectivas e desafios. In: NOBRE, Mílton Augusto de Brito; SILVA, Ricardo Augusto Dias da. (org.). O CNJ e os desafios da efetivação do direito à saúde. Belo Horizonte: Fórum, 2013, p. 85-110.

ASENSI, Felipe Dutra. Judicialização ou juridicização? As instituições jurídicas e suas estratégias na 
saúde. Physis, Rio de Janeiro, v. 20, n. 1, 2010, p. 33-55.

BARROSO, Luís Roberto. O novo Direito Constitucional Brasileiro. Belo Horizonte: Editora Fórum, 2013.

BITTAR, Eduardo C. B. O Direito na Pós-Modernidade. Rio de Janeiro: Forense Universitária, 2005.

BOSCO, Maria Goretti. Discricionariedade em políticas públicas: um olhar garantista da aplicação da lei de improbidade. Curitiba: Juruá, 2008.

BRASIL. Agência Nacional de Vigilância Sanitária. Site institucional. Disponivel em: http://portal. anvisa.gov.br/noticias/-/asset_publisher/FXrpx9qY7FbU/content/covid-19-esclarecimentos-sobrehidroxicloroquina-e-cloroquina/219201. Acesso em: 20 mar. 2020.

BRASIL. Lei Federal n. 13.979/2020, de 6 de fevereiro de 2020. Dispõe sobre as medidas para enfrentamento da emergência de saúde pública de importância internacional decorrente do coronavírus responsável pelo surto de 2019. Brasília, DF: Presidência da República, 2020.

BRASIL. Supremo Tribunal Federal. RE 657.718/MG. Relator: Min. Marco Aurélio, 25 de outubro de 2019. Diário de Justiça Eletrônico, Brasília, DF, n. 232, ata n. 162/2019, 25 out. 2019. Disponivel em: http://www.stf.jus.br/portal/jurisprudenciaRepercussao/verAndamentoProcesso. asp?incidente $=4143144 \&$ numeroProcesso $=657718$ \& classeProcesso $=$ RE\&numeroTema $=500 . \quad$ Acesso em: 17 abr. 2020.

BRASIL. Supremo Tribunal Federal. Recurso Extraordinário 566.471/RN. Relator: Min. Marco Aurélio, 11 de março de 2012. Brasília: STF, 2012. Disponível em: http://www.stf.jus.br/arquivo/cms/noticiaNoticiaStf/ anexo/RE566471.pdf. Acesso em: 17 abr. 2020.

BRASIL. Supremo Tribunal Federal. AgRg na STA 175/CE. Relator: Min. Gilmar Mendes (Presidente), 17 de março de 2010. Tribunal Pleno. Diário de Justiça Eletrônico, Brasília, DF, n. 76, ement. v. 2399-01, p. 70, 29 abr. 2010. Disponível em: http://stf.jusbrasil.com.br/jurisprudencia/9087079/agreg-na-suspensaode-tutela-antecipada-sta-175-ce. Acesso em: 10 abr. 2015.

BUCCI, Maria Paula Dallari. O conceito de políticas públicas em direito. In: BUCCI, Maria Paula Dallari (org.). Políticas públicas. Reflexões sobre o conceito jurídico. São Paulo: Saraiva, 2006, p. 01-50.

CAPPELLETTI, Mauro. Juízes Legisladores? Tradução de Carlos Alberto Álvaro de Oliveira. Porto Alegre: Sérgio Antônio Fabris Editor, 1999.

CORONAVÍRUS: Ministro da Saúde reúne-se com presidentes do Congresso e do Supremo Tribunal Federal. Brasília: Senado Notícias, 17 mar. 2020. 1 vídeo (2 min). Publicado por Senado Federal. Disponível em: https://www12.senado.leg.br/noticias/videos/2020/03/legislativo-judiciario-e-executivodiscutem-medidas-diante-da-emergencia-do-coronavirus. Acesso em: 30 mar. 2020.

DODEK, Adam M. Canada as a Constitutional Exporter: The Rise of the "Canadian Model" of Constitutionalism. Supreme Court Law Review, Canadá, n. 36, p. 309-336, 2007.

EL DIB, Regina Paolucci. Como praticar a medicina baseada em evidências. Disponível em: http:// www.scielo.br/pdf/jvb/v6n1/v6n1a01.pdf. Acesso em: 15 abr. 2020 
FARIAS, Rodrigo Nóbrega. Direito à saúde \& sua judicialização. Curitiba: Juruá, 2018.

GHOSH, Eric. Deliberative Democracy and the Countermajoritarian Difficulty: Considering Constitutional Juries. Oxford Journal of Legal Studies, v. 30, n. 02, p. 327-359, 2010.

HIDROXICLOROQUINA: CNJ divulga parecer para orientar juízes. Conselho Nacional de Justiça, Brasília, 21 mar. 2020. Notícias CNJ/Agência CNJ de Notícias. Disponível em https://www.cnj.jus.br/ hidroxicloroquina-cnj-divulga-parecer-para-orientar-juizes/. Acesso em: 2 abr. 2020.

HOGG, Peter W.; BUSHELL, Alison A. The Charter Dialogue between Courts and Legislatures (Or Perhaps the Charter of Rights Insn't Such a Bad Thing After All). Osgoode Hall Law Journal, v. 35, p. 76-107, 1997.

INSTITUTO DE ENSINO E PESQUISA (INSPER). Judicialização da Saúde no Brasil: Perfil das Demandas, Causas e Propostas de Solução. Brasília, DF: Conselho Nacional de Justiça, 2019. Disponivelem: https://www.cnj.jus.br/wp-content/uploads/2019/03/66361404dd5ceaf8c5f7049223bdc709. pdf. Acesso em: 3 abr. 2020.

MACHADO, Felipe Rangel de Souza; DAIN, Sulamis. Direito a saúde: contribuições para o estudo da judicialização. In: ASENSI, Felipe Dutra; PINHEIRO, Roseni (org.). Revista de Direito Sanitário. Rio de Janeiro: Elsevier, 2012, p. 463-489.

MENDES, Gilmar Ferreira. Homenagem à doutrina de Peter Häberle e sua influência no Brasil. Disponível em: http://www.stf.jus.br/repositorio/cms/portalStflnternacional/portalStfAgenda_pt_br/anexo/ Homenagem_a_Peter_Haberle_Pronunciamento_3_1.pdf. Acesso em: 27 jun. 2020.

PEPE, Vera Lúcia Edais et al. Caracterização de demandas judiciais de fornecimento de medicamentos "essenciais" no Estado do Rio de Janeiro, Brasil. Cad. Saúde Pública, Rio de Janeiro, v. 26, n. 3, mar. 2010. Disponível em: http://www.scielo.br/scielo.php?script=sci_arttext\&pid=S0102-311X2010000300004 \&lng=en\&nrm=iso. Acesso em: 7 abr. 2020.

PRATA, Lucília Alcione. Um novo locas de formação das políticas públicas de saúdas: o diagnóstico da saúde pela política. In: SMANIO, Gianpaolo Poggio; BERTOLIN, Patrícia Tuma Martins (org.). O Direito e as políticas públicas no Brasil. São Paulo: Atlas, 2013, p. 248-270.

SANTOS, Boaventura de Sousa. Para uma revolução democrática da Justiça. Coimbra: Almedina, 2014.

SARLET, Ingo Wolfgang; FIGUEIREDO, Mariana Filchtiner. Reserva do possível, mínimo existencial e direito a saúde: algumas aproximações. In: SARLET, Ingo Wolfgang; TIMM, Luciano Benetti. Direitos Fundamentais orçamento e "reserva do possível". Porto Alegre: Livraria do advogado, 2013, p. 13-50.

SILVA, Ricardo Augusto Dias da. O fórum nacional do judiciário como instrumento na efetivação do direito a saúde. In: NOBRE, Mílton Augusto de Brito; SILVA, Ricardo Augusto Dias da. O CNJ e os desafios da efetivação do direito à saúde. Belo Horizonte: Fórum, 2013, p. 427-450.

STRECK, Lenio Luiz. Jurisdição constitucional e hermenêutica: uma nova crítica do Direito. Porto Alegre: Livraria do Advogado, 2002.

SUNSTEIN, Cass.; VERMEULE, Adrian. Interpretations and Institutions. Public Law and Legal Theory Working Paper $n^{\circ}$ 28, Chicago, 2002. Disponível em: http://www.law.uchicago.edu/Lawecon/index.html. 
Acesso em: 15 set. 2007.

TATE, C.N. Why the expansion of judicial Power. In: TATE, C, N; VALLINDER, T. (ed.). The Global expansion of judicial Power. New York: New York University, 1995, p. 27-38.

Recebido em: 01/12/2020

Aceito em: 01/01/2021 